\title{
Antimicrobial Activity of the Anthocyanins Isolated from Purple Field Corn (Zea mays L.) Cob against Candida spp.
}

\author{
Suket, N. ${ }^{1}$, Srisook E. ${ }^{2}$, Hrimpeng, K..$^{3 *}$ \\ ${ }^{1}$ Biological Science Program, Faculty of Science, Burapha University, Chonburi 20131, Thailand \\ ${ }^{2}$ Department of Chemistry Science, Faculty of Science, Burapha University, Chonburi 20131, Thailand \\ ${ }^{3}$ Department of Mycology Science, Faculty of Science, Burapha University, Chonburi 20131, Thailand
}

\begin{abstract}
The phytochemical compounds from purple field corn (Zea mays L.) cob (PFCC), mainly grown in Phitsanulok, Thailand, were extracted with acidified $80 \%$ methanol and the anthocyanins were isolated from the extract through column chromatography with acidified absolute methanol. The PFCC extract (PFCCE) showed total anthocyanins glucoside as $6022 \mathrm{mg} / 100 \mathrm{~g}$ by colorimetric method. Three kinds of anthocyanins were detected by HPLC-DAD at $500 \mathrm{~nm}$. The antimicrobial activity of the anthocyanins from PFCC was then evaluated via macrobroth dilution method against Candida albicans ATCC 90028, two clinical isolates of Fluconazole susceptible species (C. albicans and C. tropicalis) and three clinical isolates of Fluconazole resistant species (C. glabrata, C. krusei, and C. parapsilosis). As a result, the anthocyanins exhibited a potent inhibitory activity against all the tested species with the MIC in range of $0.625-2.5 \mathrm{mg} / \mathrm{mL}$. Moreover, fungicidal activity of the anthocyanins was also observed against clinical isolates of C. tropicalis and $C$. albicans with the MFC in range of $0.625-1.25$ and $2.5 \mathrm{mg} / \mathrm{mL}$, respectively.
\end{abstract}

Keywords: Anthocyanins, Antimicrobial, Candida spp., Purple field Corn Cob

\section{Introduction}

The incidence of serious infections caused by yeast, particularly species of Candida, has increased dramatically during the past decade. Candidiasis, formerly dismissed as an simple infection occurring in denture wearers, is now one of the most common opportunistic infections in immune-compromised patients such those undergoing chemo therapy, HIV-infected persons, diabetes mellitus, broad-spectrum antibiotic therapy, transplant recipients and topical use of corticosteroid. There are topical and systemic antifungal agents that may be indicated to control candidiasis, but, the development of resistance is an emerging trend that may threaten their clinical effectiveness [1]. Candida species are a common cause of bloodstream infections. Recent surveillance had shown an increase of infections caused by C. glabrata, which had reduced susceptibility to fluconazole [2]. For millions of people that traditional medicine serves as the only opportunity for health care, plants are vital sources [1].

Purple corn (Zea mays L.) cob was the byproduct during the corn processing. It is dark purple to almost black color due to its high content of anthocyanins. Anthocyanins are a group of natural occurred pigments acidbase indicator responsible for the red-blue color of many fruits and vegetables. Anthocyanins are of interest for natural colorants and also have important implications in the field of human health. Numerous studies indicated that the potential effect these flavonoids may play a role in reducing the incidence of cardiovascular disease, cancer, hyperlipidemias and other chronic diseases through the intake of anthocyanin-rich foods [3,4 ].

This kind of purple corn is mainly grown in Thailand. In 1997, the pod of purple field corn (Zea mays L.) was found in experimental field of Rajamangala University of Technology Lanna Phitsanulok (RMUTL). The genetics of this purple field corn is based on local corn which has a starch synthesis gene and easily adapted in Thailand without using purple corn hybrid from original or other country $[5,6]$. Purple field corn cobs are considered waste in the corn processing. However, it is makes this a good source of anthocyanins [4]. Recent reports mainly analyzed the stability and structures of these anthocyanins. No information determining the antimicrobial activity of the extract of PFCC against clinical isolates Candida spp. via macro broth dilution methods.

\section{Materials And Methods}

2.1 Extraction and characterization of phytochemical compounds from purple field corn cob

Purple field corn cob powder of twenty grams extracted with method, containing $80 \%$ methanol mixture with $1 \%$ of citric acid $(1 \mathrm{M})$ for 24 hours at $4-6{ }^{\circ} \mathrm{C}$. The crude extract was obtained by filtering through Whatman No.1 filter by vacuum funnel. The solvent were evaporated methanol to dryness at $50{ }^{\circ} \mathrm{C}$ with a rotary evaporator, and the remain solvent were freeze-dried at $-50^{\circ} \mathrm{C}[7,4]$. Anthocyanins would be of natural occurred pigments acid-base indicator responsible with hydrochloric acid and sodium hydroxide, the hue color would change from red to blue by changing the $\mathrm{pH}$ of the anthocyanins [3]. The major anthocyanins initially 
characterized by TLC using butanol: acetic acid: water (4:1:4) as mobile solvent for suggested close of anthocyanins comparison with known standard $\mathrm{R}_{\mathrm{f}}$ values [8].

\subsection{Isolation and characterization of anthocyanins form crude purple field corn cob extracted}

Ten grams of crude extract were isolated by column chromatography (CC); the more polar substance was flushed with two column volumes acidified deionized distilled water. Washing the cartridge with two column volumes ethyl acetate and then the anthocyanins eluted with acidified methanol contained $(1 \%(1 \mathrm{M})$ citric acid). The methanol was evaporated to dryness at $50{ }^{\circ} \mathrm{C}$ with a rotary evaporator and freeze-dried the solvent at $-50{ }^{\circ} \mathrm{C}$ overnight kept in a bottle at $-120{ }^{\circ} \mathrm{C}$ in the dark [9] and identity of the anthocyanins were detected by HPLC-DAD.

\subsection{Preparation of anthocyanins and fluconazole for determination antifungal}

Stocked solution of anthocyanins was prepared between $0.3125 \mathrm{mg} / \mathrm{mL}-2.5 \mathrm{mg} / \mathrm{mL}$ by pipetting 50 $\mathrm{mg} / \mathrm{mL}$ were two fold dilution with $50 \%$ methanol and another pipetting $25 \mathrm{mg} / \mathrm{mL}, 12.5 \mathrm{mg} / \mathrm{mL}, 6.25 \mathrm{mg} / \mathrm{mL}$, and $3.125 \mathrm{mg} / \mathrm{mL}$. Final anthocyanins concentration was $25 \mathrm{mg} / \mathrm{mL}, 12.5 \mathrm{mg} / \mathrm{mL}, 6.25 \mathrm{mg} / \mathrm{mL}$, and 3.125 $\mathrm{mg} / \mathrm{mL}$ respectively, each concentration extract were prepared by micropipetting $100 \mu \mathrm{L}$ volumes. The final concentration was $0.3125 \mathrm{mg} / \mathrm{mL}, 0.625 \mathrm{mg} / \mathrm{mL}, 1.25 \mathrm{mg} / \mathrm{mL}$, and $2.5 \mathrm{mg} / \mathrm{mL}$ ready for placed into broth RPMI-1640 for MIC testing [10]. The drug control of fluconazole was prepared the final concentration were $128,64,32,16,8,4,2,1$, and $0.5 \mu \mathrm{g} / \mathrm{mL}$ with $1 \%$ DMSO.

\subsection{Determination of antifungal activity of anthocyanins isolated from purple field corn cob}

Standard strain of C. albican ATCC 90028 taken from Department of Microbiology Science, Faculty of Science, Burapha University, Chonburi, Thailand and five clinical isolates of five Candida spp. namely C. albicans, C. glabrata, C. krusei, C. parapsilosis, and C. tropicalis taken from Somdej Pra Boromrajathevi na Sriracha Hospital, Thailand. The inoculums preparation to frozen stokes were directly inoculated onto Sabouraud dextrose agar (SDA) plates to produce confluent growth at $35{ }^{\circ} \mathrm{C}$ for 24 hours, to ensure purity and viability, and then subcultured again to select for isolated colonies. Five colonies of $\geq 1 \mathrm{~mm}$ in diameter were suspended in $5.0 \mathrm{ml}$ of sterile $0.85 \% \mathrm{NaCl}$ and mixed thoroughly on vortex mixer for 15 to 20 seconds[11,12,13].

After adjusting the suspensions to a 0.5 McFarland, the resulted suspension was $1 \times 10^{6}$ to $5 \times 10^{6}$ $\mathrm{CFU} / \mathrm{mL}$. Then added $1 \mathrm{~mL}$ of suspension to $19 \mathrm{~mL}$ of RPMI-1640 (1:20 dilution) the resulting suspension was $1 \times 10^{4}$ to $5 \times 10^{4} \mathrm{CFU} / \mathrm{mL}$, then added inoculums-broth suspension $1 \mathrm{~mL}$ of $1 \times 10^{4}$ to $5 \times 10^{4} \mathrm{CFU} / \mathrm{mL}$ to $9 \mathrm{~mL}$ of RPMI-1640 (1:10 dilution). The final concentration was $1 \times 10^{3}$ to $5 \times 10^{3} \mathrm{CFU} / \mathrm{mL}$. Using a $5 \mathrm{~mL}$ serological pipette, added $0.1 \mathrm{~mL}(100 \mu \mathrm{L})$ of the final inoculums to each four anthocyanins and nine fluconazole concentrations for $0.1 \mathrm{~mL}(100 \mu \mathrm{L})$ mixed with RPMI $0.8 \mathrm{~mL}$ tubes. The next process included three empty tubes designated as the growth, solvent and sterility controls; growth control had $0.1 \mathrm{~mL}$ added of final inoculums to $0.9 \mathrm{~mL}$ of broth, the sterility control had $1 \mathrm{~mL}$ of broth added to tube and the solvent control had $0.1 \mathrm{~mL}$ added of final inoculums to $0.1 \mathrm{~mL}$ of solvent and $0.8 \mathrm{ml}$ of broth to the tube. After completing the vortex of the inoculums suspension was achieved to re-suspend the yeast. Using a $100 \mu \mathrm{L}$ pipette, $0.01 \mathrm{~mL}$ (10 $\mu \mathrm{L}$ ) of inoculums was placed on a SDA plate, covering the entire surface. All the tubes and invert plates were incubated at $35^{\circ} \mathrm{C}$ for 24 to 48 hours, or until colonies are visible for accurate counting. After inoculating the tubes, they were read for MIC (Determining MIC from the lowest fluconazole and anthocyanins concentration with no turbidity and suspensions). The MICs for all anthocyanins and fluconazole were the lowest concentrations $[11,14,15,16]$.

After MIC were read, using the entire contents concentrations above MIC to determine of MFC. A micropipette was used, and removed $20 \mu \mathrm{L}$ from the MIC tube, each higher concentration tubes, and the growth control tube drop over SDA plate and incubated at $35^{\circ} \mathrm{C}$. Read plates when colonies on the growth control plate are visible, usually $24 \mathrm{~h}$, and again at $48 \mathrm{~h}$. The MFC was defined as the lowest anthocyanins and fluconazole concentration that resulted in a $99.9 \%$ reduction in the starting inoculums, any plate with one colony or fewer were negative. The lowest concentration for which sub-cultured negative was the MFC $[15,16]$. All the experiments were repeated twice, including three controls.

\section{Results And Discussion}

\subsection{Percent yield of anthocyanins from PFCC}

The dark purple (Fig.1) powder ten grams of crude extracted purple field corn cob was added to the cartridge column chromatography. A solution of $1 \%$ citric acid (1M) in distill water was used to flushed sugars and acids was checked for fraction exhibiting done for dark color, after which ethyl acetate was used to remove the phenolic was checked for fraction exhibiting finish dark brown color. Finally, the anthocyanins were eluted using $1 \%$ citric acid $(1 \mathrm{M})$ in methanol, the product were magenta color powder $0.8 \mathrm{~g}$ ( $8 \%$ yield) after freeze 
dried (Fig.1).

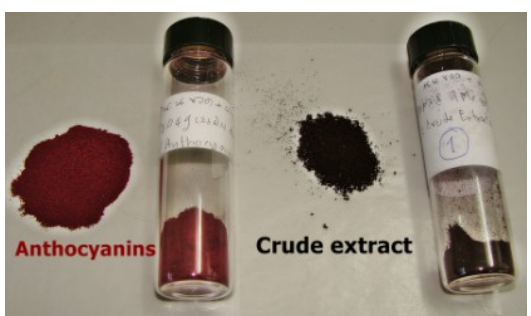

Figure 1 Characteristic of crude extract (dark purple) and isolated PFCC anthocyanins (magenta color)

\subsection{Characterization of phytochemical compounds from crude PFCCE}

Anthocyanins were a major of crude extract has been showed acid-base indicator by color changed, $\mathrm{pH}$ 1-4 were red, $\mathrm{pH}$ 5-6 were purple pink, $\mathrm{pH} 7$ were colorless, $\mathrm{pH}$ 8-9 were bluish green, $\mathrm{pH}$ 10-12 were yellow brown (Table 1).

Table 1 Results of $\mathrm{pH}$ indicator characteristic from PFCCE

$$
\mathrm{pH} \text { ranges Color of anthocyanins }
$$

\begin{tabular}{cc}
\hline $1-4$ & red \\
$5-6$ & purple pink \\
7 & colorless \\
$8-9$ & bluish green \\
$10-11$ & yellow brown \\
\hline
\end{tabular}

The acid-base indicator property of the PFCCE was also examined and being found as a predominant group of PFCC pigments [17]. This characteristic confounds isolation of specific anthocyanin. The initially screening again with using $R_{f}$ value on TLC (Fig. 2) had pigment $R_{f}$ values $0.81,0.72,0.69$ and 0.67 close to anthocyanins $R_{f}$ values comparison with $R_{f}$ values of known standard [8].

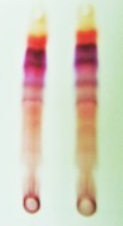

Figure 2 Thin Layer Chromatography of crude PFCCE

\subsection{Characterization of anthocyanins form PFCCE}

The PFCCE showed total of anthocyanins glucoside as $6022 \mathrm{mg} / 100 \mathrm{~g}$ with colorimetric method by Central Laboratory (Thailand) CO., Ltd. Chiangmai Branch. Three kinds of anthocyanins were detected by HPLC-DAD at $500 \mathrm{~nm}$. For this study we found the important three major type anthocyanins with reliable information which support in this education at retention times were $20.108,23.892$ and 26.263 minutes for suggest of cyaniding-3-glucoside, pelargonidin-3- glucoside and peonidin-3- glucoside respectively with compare of known standard (Fig 3). 


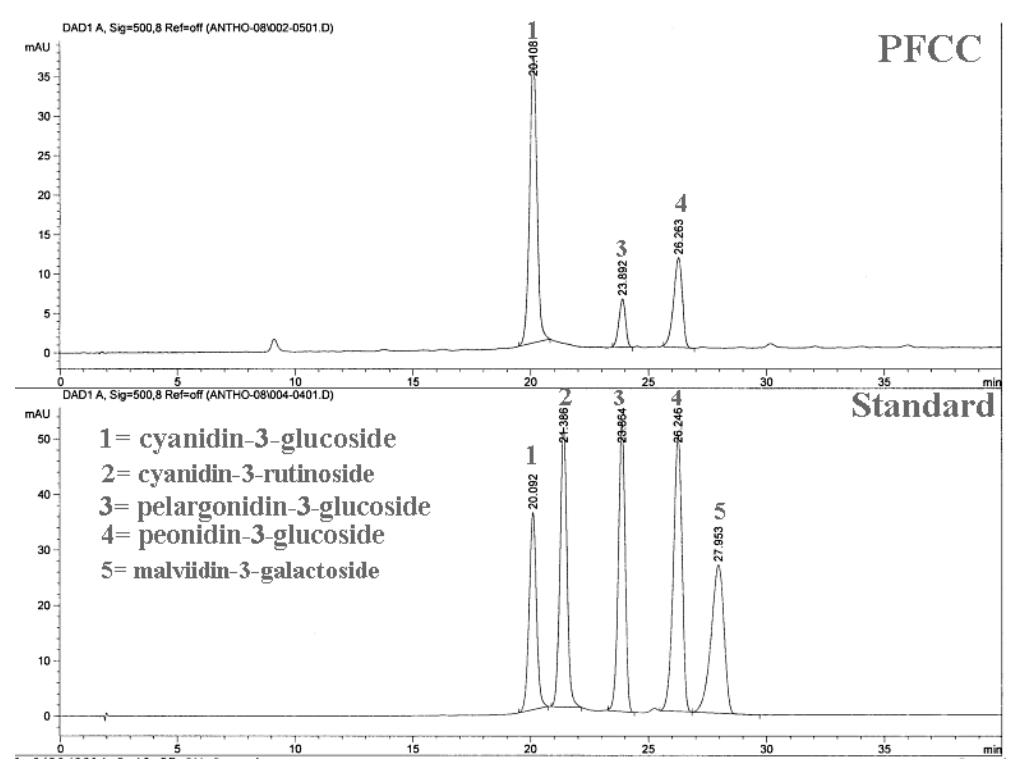

Figure 3 The HPLC-DAD profile of anthocyanin at $500 \mathrm{~nm}$

\subsection{Determination of antifungal activity of anthocyanins for macro broth dilution}

The previously established CLSI of MIC interpretive break points for Candida spp. tested against fluconazole were based on an analysis of treatment in which MIC breakpoint of $\leq 8 \mu \mathrm{g} / \mathrm{mL}$ define susceptibility (S) and of $\geq 64 \mu \mathrm{g} / \mathrm{mL}$ define resistance (R), with MICs of between 16 and $32 \mu \mathrm{g} / \mathrm{mL}$ reflecting dose-dependent susceptibility (SDD) $[18,19]$. The antimicrobial activity of the anthocyanins from PFCC was then evaluated via macrobroth dilution method against Candida albicans ATCC 90028, two clinical isolates of fluconazole susceptible species (C. albicans and C. tropicalis) and three clinical isolates of fluconazole resistant species (C. glabrata, C. krusei, and C. parapsilosis). As a result, the anthocyanins exhibited a potent inhibitory activity against all the tested species with the MIC in range of $0.625-2.5 \mathrm{mg} / \mathrm{mL}$. Moreover, fungicidal activity of the anthocyanins was also observed against clinical isolates of C. tropicalis and C. albicans (Fig.4) with the MFC in range of $0.625-1.25$ and $2.5 \mathrm{mg} / \mathrm{mL}$, respectively (Table 2 ).

Table 2 MIC and MFC range of anthocyanins and fluconazole concentrations

\begin{tabular}{|c|c|c|c|c|}
\hline \multirow[t]{2}{*}{ Candida spp. } & \multicolumn{2}{|c|}{ Anthocyanins (mg/mL) } & \multicolumn{2}{|c|}{ Fluconazole $(\mu \mathrm{g} / \mathrm{mL})$} \\
\hline & MIC & $\mathrm{MFC}$ & MIC & MFC \\
\hline $\begin{array}{l}\text { C.albicans } \\
\text { (ATCC 90028) }\end{array}$ & 2.5 & $>2.5$ & $1-2$ & $>128$ \\
\hline C. albicans & $0.625-1.25$ & 2.5 & $8-16$ & 64 \\
\hline C. glabrata & $0.625-1.25$ & $>2.5$ & 128 & $>128$ \\
\hline C. krusei & 2.5 & $>2.5$ & 128 & $>128$ \\
\hline C. parapsilosis & $1.25-2.5$ & $>2.5$ & 128 & $>128$ \\
\hline C. tropicalis & $0.625-1.25$ & $0.625-1.25$ & $8-16$ & 32 \\
\hline
\end{tabular}

The activity of Candida spp. With MIC in range of $0.625-2.5 \mathrm{mg} / \mathrm{mL}$ inhibition activity of anthocyanins again Candida spp. was not depend on the fluconazole susceptibility pattern of microorganism.

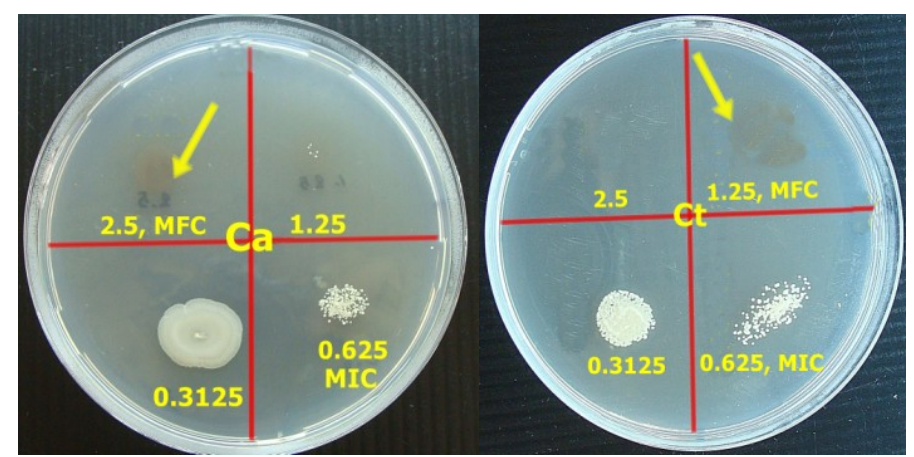

Figure4 Fungicidal activity of C. albicans (Ca) and C. tropicalis $(\mathrm{Ct})(\mathrm{MFC}=\rightarrow)$ 


\section{Conclusion}

The bioactive of total anthocyanin-3-glucoside from PFCCE was activity again on Candida spp. namely Candida albicans ATCC 90028, and five urine specimen clinical isolated of five candida spp.; two species are C. albicans, and C. tropicalis, the MFC rang was defined $2.5 \mathrm{mg} / \mathrm{mL}$ and $0.625-1.25 \mathrm{mg} / \mathrm{mL}$ respectively, and another four species inhibited the growth of C. albicans ATCC 90028, C. glabrata, C. krusei, and C. parapsilosis, the MIC was defined the lowest anthocyanins range as $2.5 \mathrm{mg} / \mathrm{mL}, 0.625-1.25 \mathrm{mg} / \mathrm{mL}, 2.5$ $\mathrm{mg} / \mathrm{mL}$, and $1.25-2.5 \mathrm{mg} / \mathrm{mL}$ respectively. It is now widely accepted that the resistance to fluconazole was relatively common in Candida spp. This experiment was founded three species which C. glabrata, C.krusei, and C. parapsilosis were resistance to fluconazole. In addition, the most interesting result was the susceptibility of C. glabrata to anthocyanins which is resistance to fluconazole. In the future, we are hopefully that anthocyanins from purple field corn cob extracts are vital sources, safety and suggested them as sources of new nontoxic pharmaceuticals for threat infection cause by Candida spp.

\section{Acknowledgements}

We are grateful to thank Faculty of Science, Burapha University and Rajamangala University of Technology Lanna Phitsanulok (RMUTL) for supporting.

\section{References}

[1]. Atai, Z., Atapour, M., \& Mohseni M. Inhibitory effect of ginger extract on Candida albicans. American Journal of Applied Sciences, 6 (6), 2009. 1067-1069.

[2]. Lyon, G., M., Karatela, S., Sunay, S., \& Adiri, Y. Antifungal susceptibility testing of Candida isolates from the Candida surveillance study. Journal of Clinical Microbiology, 48(4), 2010, 1270-1275.

[3]. Yang, Z, Han, H., Gu, Z., Fan, G., \& Chen, Z. Thermal degradation kinetics of aqueous anthocyanins and visual color of purple corn (Zea may L.) cob. Innovative Food Science \& Emerging Technologies, 9, 2008. 341-347.

[4]. Yang, Z., Fan, G., Gu, Z., Han, Y., \& Chen, Z. Optimization extracted of anthocyanins rom purple corn (Zea mays L.) cob using tristimulus colorimetry. Euro Food Res Technol, 227, 2008, 409-415.

[5]. Komsan Amnueysit. Development of Purple Field Corn Cob. Rajamangala University of Technology Lanna (RMUTL) Phitsanulok., 1997.

[6]. Komsan Amnueysit. Retrieved, October 28, 2007 , From http://serv.nan.rmutl.ac.th

[7]. Merzlyak M., N., Chivkunova, O., B., Solovchenko A., V., \& Naqvi, K., R. Light absorption by anthocyanins in juvenile, stressed, and senescing leaves. Journal Experimental Botany, 59 (14), 2008. 3903-3911.

[8]. Delpech R. The Importance of red pigments to plant life: experiments with anthocyanins. Journal of Biological Education,34(4), 2000, 206-210.

[9]. Luis, E., Rodriguez-Saona, \& Wrolstad, R. E. Current Protocols in Food Analytical Chemistry.John Wiley \& Son, Inc., 2001.

[10]. Zhao, X., Zhang, C., Guigas, C., Ma, Y., Corrales M., Tauscher, B., \& Hu, X. Composiytion, antimicrobial activity, and antiproliferative capacity of anthocyanin extracts of purple corn (Zea mays L.) from China. Eur Food Res Technol, 228, 2009, 759765 .

[11]. Fromtling,R., A., Galgiani,J., N., Pfaller, M., A., Espinel-Ingroff, A., Bartizal,K., F., Bartlett, M., S., Body, B., A., Frey, C., Hall, G., Roberts., G., D., Nolte, F., B., Odds, F., C., Rinaldi, M., G., Sugar, A., M., \& Villareal, K. Multicenter evaluation of a broth macrodilution antifungal susceptibility test for yeast. Antimicrobial Agents and Chemotherapy, 37(1), 1993, 39-45.

[12]. Barry, A., Bille, J., Brown, S., Ellis, D., Meis, J., Pfaller, M., Rennie, R., Rinaldi, M., Rogers, T., \& Traczewski M. Quality control limits for fluconazole disk susceptibility test on Mueller-Hinton agar with glucose and methylene blue. Journal of Clinical Microbiology, 47 (7), 2003, 3410-3412.

[13]. Pfaller, M., A., Messer, S., A., Boyken, L., Rice, C., Tendolkar, S., Hollis, R., J., \& Diekema, D., J. Evaluation of the NCCLS M44P disk diffusion Method for determining susceptibilities of 276 clinical isolates of Cryptococcus neoformans to fluconazole. Journal of Clinical Microbiology , 42 (1), 2004, 380-383.

[14]. Isham, N., \& Ghannoum, M., A. Determination of MICs of aminocandin for Candida spp. And filamentous fungi. Journal of Clinical Microbiology, 44(12), 2006, 4342-4344.

[15]. Doctor Fungus. Retrieved September 4,2011 , from http://www.doctorfungus.org/thelabor/sec14.pdf

[16]. Pfaller, M., A., Grant, C., Morthland, V., \&Rhine-Chalberg, J. Comparative evaluation of alternative methods for broth dilution susceptibility testing of fluconazole against Candida albicans. Journal of Clinical Microbiology, 32 (2), 1994,506-509.

[17]. Castaneda-Ovando, A., Pacheco-Hernandez, M., L., Paez-Hernandez, M.E., Rodriguez, J. A., \& Galan-Vidal, C. A.. Chemical studies of anthocyanins: A review. Food Chemistry, 113, 2009, 859-871.

[18]. Pfaller, M., A., Shehan, D., J. \& Diekema, D., J. Interpretive Breakpoint for Fluconazole and Candida Revisited: a Blueprint for the Future of Antifungal Susceptibility Testing. Journal of Clinical Microbiology, 9 (2), 2006, 435-447.

[19]. Lyon, G., M., Karatela, S., Sunay, S., \& Adiri, Y. Antifungal susceptibility testing of Candida isolates from the Candida surveillance study. Journal of Clinical Microbiology, 48(4), 2010, 1270-1275. 